\title{
Fatores de risco para desenvolver pneumonia associada à ventilação mecânica em pacientes internados na Unidade de Terapia Intensiva
}

Risk factors for developing ventilator-associated pneumonia in patients admitted to the Intensive Care Unit

Factores de riesgo para desarrollar neumonía asociada a ventilador en pacientes ingresados en la Unidad de Cuidados Intensivos

Airton César Leite

ORCID: https://orcid.org/0000-0001-7184-8488 Centro Universitário Santo Agostinho, Brasil E-mail: ainton.cesar2014@gmail.com

Mariana Pereira Barbosa Silva ORCID: https://orcid.org/0000-0003-0852-8099 Universidade Estadual do Piauí, Brasil E-mail: marianapbsilvaa@gmail.com Geovana Maria Rodrigues de Sousa ORCID: https://orcid.org/0000-0001-6398-8560

Centro Universitário Santo Agostinho, Brasil E-mail: geovanamaria08@hotmail.com

Marciele de Lima Silva

ORCID: https://orcid.org/0000-0003-2827-5316 Instituto de Educação Superior da Paraíba, Brasil E-mail: marcieledelsilva@gmail.com

Samuel Lopes dos Santos ORCID: https://orcid.org/0000-0003-3375-9171 Universidade Federal do Piauí, Brasil E-mail: samuellopes121314@gmail.com

Maria Vitalina Alves de Sousa ORCID: https://orcid.org/0000-0003-4448-2489 Centro Universitário INTA, Brasil E-mail: enf.vitalinaalves@gmail.com

Laiana Dias Prudêncio

ORCID: https://orcid.org/0000-0002-0016-3868

Centro Universitário Maurício de Nassau, Brasil E-mail: laianadias568@gmail.com

Diego Bruno Brito Cerqueira

ORCID: https://orcid.org/0000-0002-8083-1634 Faculdade Integral Diferencial, Brasil E-mail: diegocerqueirafisioterapeuta@hotmail.com

Winícius de Carvalho Alves

ORCID: https://orcid.org/0000-0003-3118-5696

Centro Universitário Santo Agostinho, Brasil

E-mail: winiciusdecarvalho@hotmail.com

Cilmara Gomes Martins da Silva

ORCID: https://orcid.org/0000-0002-9415-4099 Faculdade de Tecnologia e Educação Superior Profissional, Brasil E-mail: silmaragomes09@outlook.com

Antônio Filho Alves Rodrigues ORCID: https://orcid.org/0000-0001-7714-9901 Universidade Federal do Piauí, Brasil E-mail: filho.nino@hotmail.com

William Gomes Silva

ORCID: https://orcid.org/0000-0001-5078-8535 Associação de Ensino Superior do Piaú, Brasil E-mail: william-wgs@hotmail.com

Jailson Pereira de Sousa

ORCID: https://orcid.org/0000-0001-7650-7017 Associação de Ensino Superior do Piauí, Brasil

E-mail: pereiradesousajailson@gmail.com 


\author{
Weberton Dorásio Sobrinho \\ ORCID: https://orcid.org/0000-0003-0619-7214 \\ Universidade de Rio Verde, Brasil \\ E-mail: dorasioweberton@gmail.com \\ Yasmim Vieira dos Santos \\ ORCID: https://orcid.org/0000-0002-6661-7383 \\ Centro Universitário Maurício de Nassau, Brasil \\ E-mail: mimsayvieira@gmail.com \\ Joelma Maria dos Santos da Silva Apolinário \\ ORCID: https://orcid.org/0000-0001-9521-9432 \\ Faculdade Maurício de Nassau, Brasil \\ E-mail: jo.silva00@hotmail.com \\ Yorran Ferreira Brito \\ ORCID: https://orcid.org/0000-0003-1475-3049 \\ Associação de Ensino Superior do Piauí, Brasil \\ E-mail: yorrandu13@hotmail.com \\ Beatriz Cristina Carvalho Macêdo \\ ORCID: https://orcid.org/0000-0003-3756-2624 \\ Centro Universitário Uninovafapi, Brasil \\ E-mail: beatrizmaccedo1@gmail.com \\ Aryanna Quadros Maniçoba \\ ORCID: https://orcid.org/0000-0003-0575-3485 \\ Centro Universitário Uninovafapi, Brasil \\ E-mail: aryannaquadros.61@gmail.com \\ Mikaella Carvalho de Sousa \\ ORCID: https://orcid.org/0000-0002-3503-6930 \\ Centro Universitário Santo Agostinho, Brasil \\ E-mail: mikaellasousa623@gmail.com \\ Tamara Saraiva de Assis \\ ORCID: https://orcid.org/0000-0002-1624-2755 \\ Universidade Federal do Vale do São Francisco, Brasil \\ E-mail: tamsaraiva2@gmail.com \\ Janaiara de Sousa Almeida \\ ORCID: https://orcid.org/0000-0003-2082-7622 \\ Universidade Estadual do Piauí, Brasil \\ E-mail: jnapop14@gmail.com \\ Camila Isnaide Pinheiro Campelo \\ ORCID: https://orcid.org/0000-0001-5059-5725 \\ Universidade Estadual do Piauí, Brasil \\ E-mail: isnayd@gmail.com \\ Luiz Carlos Pereira de Sousa \\ ORCID: https://orcid.org/0000-0002-5742-6315 \\ Centro Universitário de Patos, Brasil \\ E-mail: luizcarlosperreira.15@gmail.com
}

\title{
Resumo
}

Analisar as evidências científicas publicadas sobre os fatores de risco para desenvolver pneumonia associada à ventilação mecânica em pacientes internados na Unidade de Terapia Intensiva. O presente estudo trata de uma revisão bibliográfica do método revisão integrativa da literatura, realizado nos meses entre maio a outubro de 2021. A busca efetuou-se, através da - BVS, utilizando as bases de dados LILACS, BDENF, por meio da SCIELO. Aderindo-se através dos descritores/palavras chaves: "Pneumonia", "Ventilação Mecânica", "Unidade de Terapia Intensiva", combinados com o operador booleano "AND”. Os fatores de risco da PAVM são idade avançada acima de setenta anos; coma; nível de consciência; intubação e reintubação traqueal; condições imunitárias; uso de drogas imunodepressoras; choque; gravidade da doença; antecedência de Doença Pulmonar Obstrutiva Crônica (DPOC); tempo prolongado de ventilação mecânica maior que sete dias; aspirado do condensado contaminado dos circuitos do ventilador; desnutrição; contaminação exógena; antibioticoterapia como profilaxia; colonização microbiana; cirurgias prolongadas; aspiração de secreções contaminadas; colonização gástrica e aspiração desta, o pH gástrico (maior que 4). As ações de enfermagem para o controle da PAV são de extrema importância dentro do contexto terapêutico e de cuidado no hospital. A educação continuada e a adoção de medidas baseadas em evidências científicas, bem como protocolos em saúde, correspondem aos melhoramentos dos aspectos em questão. Nota-se a importância do (NSP) e CCIH que exibem indicadores, fiscalização dos setores, elaboração de protocolos, bundles de prevenção que são práticas que comprovadamente que evitam a PAV, atividades de educação permanente e continuada vinculada à promoção de saúde.

Palavras-chave: Pneumonia; Ventilação mecânica; Unidade de Terapia Intensiva.

\section{Abstract}

To analyze published scientific evidence on risk factors for developing ventilator-associated pneumonia in patients admitted to the Intensive Care Unit. This study is a literature review of the integrative literature review method, 
carried out in the months between May and October 2021. The search was carried out through the - VHL, using the LILACS, BDENF databases, through SCIELO. Adhering through the descriptors/key words: "Pneumonia", "Mechanical Ventilation", "Intensive Care Unit", combined with the Boolean operator "AND". Risk factors for VAP are advanced age above seventy years of age; with the; level of consciousness; intubation and tracheal reintubation; immune conditions; use of immunosuppressive drugs; shock; disease severity; advance of Chronic Obstructive Pulmonary Disease (COPD); prolonged period of mechanical ventilation greater than seven days; aspirated the contaminated condensate from the fan circuits; malnutrition; exogenous contamination; antibiotic therapy as prophylaxis; microbial colonization; prolonged surgeries; aspiration of contaminated secretions; gastric colonization and aspiration thereof, gastric $\mathrm{pH}$ (greater than 4). Nursing actions to control VAP are extremely important within the therapeutic and care context in the hospital. Continuing education and the adoption of measures based on scientific evidence, as well as health protocols, correspond to improvements in the aspects in question. Note the importance of the (NSP) and CCIH, which display indicators, inspection of sectors, development of protocols, prevention bundles, which are practices that have been proven to prevent VAP, permanent and continuing education activities linked to health promotion.

Keywords: Pneumonia; Mechanical ventilation; Intensive Care Unit.

\section{Resumen}

Analizar la evidencia científica publicada sobre los factores de riesgo de desarrollar neumonía asociada a ventilador en pacientes ingresados en la Unidad de Cuidados Intensivos. Este estudio es una revisión bibliográfica del método de revisión integradora de la literatura, realizada en los meses comprendidos entre mayo y octubre de 2021. La búsqueda se realizó a través de la BVS, utilizando las bases de datos LILACS, BDENF, a través de SCIELO. Adhiriéndose a los descriptores / palabras clave: "Neumonía", "Ventilación Mecánica", "Unidad de Cuidados Intensivos", combinado con el operador booleano "Y". Los factores de riesgo de NAV son la edad avanzada por encima de los setenta años; con el; nivel de consciencia; intubación y reintubación traqueal; condiciones inmunes; uso de fármacos inmunosupresores; choque; gravedad de la enfermedad; avance de la Enfermedad Pulmonar Obstructiva Crónica (EPOC); período prolongado de ventilación mecánica superior a siete días; aspirado el condensado contaminado de los circuitos del ventilador; desnutrición; contaminación exógena; terapia con antibióticos como profilaxis; colonización microbiana; cirugías prolongadas; aspiración de secreciones contaminadas; colonización gástrica y aspiración de la misma, pH gástrico (mayor de 4). Las acciones de enfermería para el control de la NAV son de suma importancia dentro del contexto terapéutico y asistencial en el hospital. La educación continua y la adopción de medidas basadas en la evidencia científica, así como los protocolos de salud, corresponden a mejoras en los aspectos en cuestión. Nótese la importancia del (NSP) y CCIH, que muestran indicadores, inspección de sectores, desarrollo de protocolos, paquetes de prevención, que son prácticas que han demostrado ser preventivas de NAV, actividades de educación permanente y continúa vinculadas a la promoción de la salud.

Palabras clave: Neumonía; Ventilacion mecanica; Unidad de Terapia Intensiva.

\section{Introdução}

As Unidades de Terapia Intensiva (UTI's) surgiram como resposta para o tratamento de pacientes graves, constituindo áreas hospitalares destinadas aos pacientes críticos que necessitam de cuidados altamente complexos, além de um controle rigoroso. Desse modo, pode-se entender a assistência ventilatória como a manutenção da oxigenação e/ou ventilação dos pacientes de maneira artificial até que estes estejam capacitados a reassumi-las. Torna-se essa assistência importante para os pacientes internados nas Unidades de Terapia Intensiva com insuficiência respiratória (Santos et al., 2018).

No ambiente hospitalar, o tratamento de pacientes críticos em Unidade de Terapia Intensiva (UTI) vem se aperfeiçoando quanto a equipamentos e ferramentas destinados ao diagnóstico, tratamento e recuperação do paciente. Uma das principais ferramentas usadas em pacientes graves em UTI é a ventilação mecânica (VM). Porém, apesar de ser um mecanismo necessário para a sobrevivência, podem ocorrer complicações, dentre estas, a pneumonia associada à ventilação mecânica (PAV). Dentre as infecções relacionadas à assistência à saúde (IRAS), a pneumonia pode gerar consequências ao paciente, já que é uma grave infecção que apresenta múltiplas causas e grande impacto nas taxas de morbimortalidade, aumento dos custos assistenciais e tempo de internação. Os primeiros cinco dias de VM são os de maior PAV, alcançando 3\% ao dia, decaindo para $2 \%$ ao dia entre 5 e 10 dias de VM e 1\% após 10 dias. Pode ocorrer PAV de início precoce (nos primeiros 4 dias), sendo que nesta predominam agentes com padrão multissensível, ou PAV de início tardio (após 4 dias de ventilação) com predomínio de agentes com perfil multirresistente (Montini et al., 2020). 
A pneumonia associada à ventilação mecânica é uma infecção que se inicia de 48 a 72 horas após a intubação endotraqueal e o estabelecimento da ventilação mecânica invasiva, e que tem, como agente causador, um microrganismo que não estava presente ou incubado e cuja ocorrência, geralmente, decorre da aspiração de secreções das vias áreas superiores, do refluxo gastrintestinal e da inoculação de material exógeno contaminado. Classificam-se os fatores de risco para o seu desenvolvimento como modificáveis e não modificáveis : os não modificáveis relacionam-se à idade e às condições de saúde do paciente, enquanto os modificáveis incluem o tempo prolongado de ventilação mecânica, as intubações endotraqueais subsequentes, a sondagem nasogástrica, a imobilização, o posicionamento supino, o uso de agentes antimicrobianos, o uso de medicamentos antiácidos, a sedação, a inadequada higienização das mãos pelos profissionais de saúde e os maus cuidados de assepsia durante a intubação, a aspiração de vias aéreas e o manuseio do respirador (Dutra et al., 2019).

Segundo Rodrigues, Neto, Santos, Knibel (2009), a pneumonia é a principal causa de infecção nosocomial em UTIs, ocorrendo, em mais de $90 \%$ dos casos, em pacientes submetidos à intubação endotraqueal e ventilação mecânica (VM). Devido a sua relevância clínica e seu perfil epidemiológico, a pneumonia associada à ventilação mecânica (PAVM) é estudada como uma entidade clínica distinta dentro das pneumonias nosocomiais, representando um dos principais desafios enfrentados pelo intensivista em sua prática diária.

Do ponto de vista epidemiológico, a PAVM afeta 8 a $20 \%$ dos pacientes de UTI e aproximadamente $27 \%$ dos indivíduos ventilados mecanicamente. A mortalidade varia de 20 a 50\%, e pode chegar a 70\% quando os agentes etiológicos são multirresistentes. Dentre os fatores de risco, estão o tempo de ventilação mecânica, presença de doença pulmonar crônica, sepse, síndrome do desconforto respiratório agudo (SDRA), doença neurológica, trauma, uso de antimicrobiano prévio e transfusão de sangue. De maneira geral, a PAVM é uma entidade clínica de difícil diagnóstico, possuindo como critérios obrigatórios: hipertermia ou hipotermia, leucocitose ou leucopenia, alteração na quantidade ou qualidade do escarro, e infiltrado novo ou persistente no raio $\mathrm{X}$ de tórax. A identificação do agente etiológico apresenta-se como critério opcional, podendo ser obtida por lavado broncoalveolar, escovado protegido ou aspirado traqueal (Kock et al., 2017).

No cenário mundial, a PAV é considerada como um dos efeitos indesejáveis mais preocupantes em UTI, por causar danos potenciais na saúde dos indivíduos acometidos por essa complicação e também na sustentabilidade organizacional, devido ao aumento na morbidade e mortalidade, no tempo de internação e nos custos hospitalares. Com isso, a PAV é considerada como infecção relacionada à assistência à saúde (IRAS) que compromete a segurança do paciente (Maran et al., 2021).

Dessa forma, a equipe multiprofissional exerce papel fundamental no que diz respeito à prevenção das infecções no ambiente hospitalar, o que implica na adoção de medidas preventivas padronizadas, treinamento de equipes, educação continuada no processo assistencial com vistas a evitar falhas neste processo, uma vez que a PAV é de origem infecciosa com diagnostico multicausal (Liz et al., 2020).

Diante da temática em discussão, surge como questão norteadora do estudo: "Quais os fatores de risco para desenvolver pneumonia associada à ventilação mecânica em pacientes internados na Unidade de Terapia Intensiva"? Assim, o objetivo do presente estudo é analisar as evidências científicas publicadas sobre os fatores de risco para desenvolver pneumonia associada à ventilação mecânica em pacientes internados na Unidade de Terapia Intensiva.

A realização do presente estudo relacionado à temática, é essencial para a construção coletiva do conhecimento, pois, o estudo possibilita a sociedade acadêmica e cientifica a ampliar o conhecimento sobre os fatores de risco para desenvolver pneumonia associada à ventilação mecânica em pacientes internados na Unidade de Terapia Intensiva. Desse modo, o estudo trará contribuições pertinentes, na medida em que acrescentará as evidências científicas discussões relevantes a respeito dessa temática tão importante. 


\section{Metodologia}

O presente estudo trata de uma revisão bibliográfica do método revisão integrativa da literatura, realizado nos meses entre maio a outubro de 2021. A revisão configura-se, portanto, como um tipo de revisão da literatura que reúne achados de estudos desenvolvidos mediante diferentes metodologias, permitindo aos revisores sintetizar resultados sem ferir a filiação epistemológica dos estudos empíricos incluídos. Para que esse processo concretize-se de maneira lógica, isenta de desatinos epistemológicos, a revisão requer que os revisores procedam à análise e à síntese dos dados primários de forma sistemática e rigorosa (Soares et al., 2014).

A revisão da literatura serve para reconhecer a unidade e a diversidade interpretativa existente no eixo temático em que se insere o problema em estudo, para ampliar, ramificar a análise interpretativa, bem como para compor as abstrações e sínteses que qualquer pesquisa requer colaborando para a coerência nas argumentações do pesquisador. Nesse sentido, a revisão integrativa é um método que tem como finalidade reunir e sintetizar resultados de pesquisas sobre um delimitado tema ou questão, de maneira sistemática e ordenada e abrangente, contribuindo para o aprofundamento do conhecimento do tema investigado (Ferenhof \& Fernandes, 2016).

O processo de revisão da literatura requer a elaboração de uma síntese pautada em diferentes tópicos, capazes de criar uma ampla compreensão sobre o conhecimento. A revisão da literatura é um primeiro passo para a construção do conhecimento científico, pois é através desse processo que novas teorias surgem, bem como são reconhecidas lacunas e oportunidades para o surgimento de pesquisas num assunto específico (Botelho et al., 2011).

A revisão integrativa é uma ferramenta de investigação que permite à procura, a avaliação crítica e a síntese de evidências disponíveis sobre o tema investigado, em que o produto final é o estado do conhecimento, a implementação de intervenções efetivas na prestação de cuidados e na redução de custos. Além disso, permite a identificação de fragilidades, que poderão conduzir ao desenvolvimento de futuras investigações (Sousa et al., 2017).

A revisão integrativa permite que o leitor reconheça os profissionais que mais investigam determinado assunto, separar o achado científico de opiniões e ideias, além de descrever o conhecimento no seu estado atual, promovendo impacto sobre a prática clínica. Este método de pesquisa proporciona aos profissionais de saúde dados relevantes de um determinado assunto, em diferentes lugares e momentos, mantendo-os atualizados e facilitando as mudanças na prática clínica como consequência da pesquisa. Dessa forma, acredita-se que a revisão integrativa é uma ferramenta importante no processo de comunicação dos resultados de pesquisas, facilitando a utilização desses na prática clínica, uma vez que proporciona uma síntese do conhecimento já produzido e fornece subsídios para a melhoria da assistência à saúde (Mendes et al., 2008). 
Figura 1. Fluxograma fases distintas da revisão integrativa.

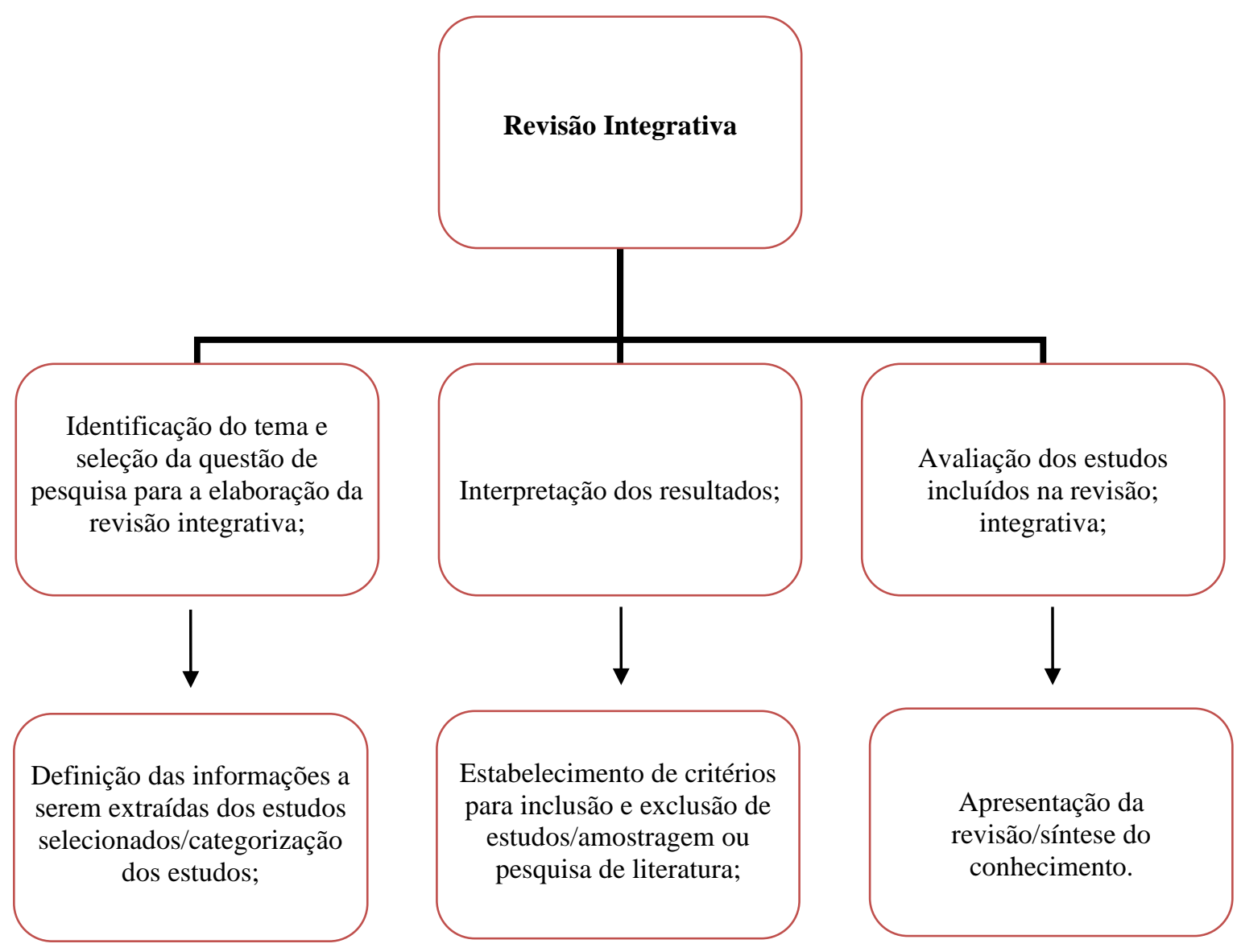

Fonte: Mendes et al. (2008).

A revisão integrativa é um tipo de pesquisa que fornece informações mais amplas de maneira sistemática, ordenada e abrangente, sobre um assunto ou tema, com a finalidade de sintetizar resultados obtidos em pesquisa sobre temas ou questões. A definição das informações a serem extraídas dos estudos selecionados por categorização; avaliação dos estudos incluídos; interpretação dos resultados; e apresentação da revisão/síntese do conhecimento (Ercole et al., 2015).

Estudo elaborado com abordagem qualitativa tornando-se importante a interpretação por parte do pesquisador com suas opiniões sobre o fenômeno em estudo. Neste tipo de pesquisa destacam-se algumas características como: a pesquisa qualitativa, em geral, ocorre no ambiente natural com coleta direta de dados e o pesquisador é o principal instrumento; os dados coletados são preferencialmente descritivos; a preocupação do processo é predominante em relação à do produto; a análise de dados e informações tende a seguir um processo indutivo (Pereira et al., 2018).

A pesquisa qualitativa envolve uma abordagem interpretativa do mundo, o que significa que seus pesquisadores estudam as coisas em seus cenários naturais, tentando entender os fenômenos em termos dos significados que as pessoas a eles conferem. A pesquisa qualitativa atribui importância fundamental aos depoimentos dos atores sociais envolvidos, aos discursos e aos significados transmitidos por eles. Nesse sentido, esse tipo de pesquisa preza pela descrição detalhada dos fenômenos e dos elementos que o envolvem (Augusto et al., 2014).

De acordo com Souza et al., (2010), a ser realizada nas seguintes etapas: 1- Elaboração da pergunta norteadora; 2Busca nas bases de dados e amostragem; 3- Coleta de dados, 4- Análise crítica. 
Para responder à questão norteadora do estudo: "Quais os fatores de risco para desenvolver pneumonia associada à ventilação mecânica em pacientes internados na Unidade de Terapia Intensiva"? Aplicou-se os descritores/palavras-chaves: "Pneumonia", "Ventilação Mecânica", "Unidade de Terapia Intensiva".

A busca efetuou-se, através da Plataforma da Biblioteca Virtual em Saúde - BVS, utilizando as bases de dados Literatura Latino-Americana e do Caribe em Ciências da Saúde (LILACS), Base de Dados de Enfermagem (BDENF), por meio da - Scientific Electronic Library Online (SCIELO). Aderindo-se através dos descritores/palavras chaves: "Pneumonia", "Ventilação Mecânica", "Unidade de Terapia Intensiva", combinados com o operador booleano "AND".

Os critérios de inclusão estabelecidos foram: artigos originais disponibilizados na íntegra, completos, que abrangessem a temática e na forma online, publicados nos idiomas português, inglês e espanhol, publicações que respondiam a questão norteadora do estudo. Os critérios de exclusão estabelecidos na seleção foram: artigos incompletos, artigos duplicados, teses, dissertações, monografias, manuais, e publicações que não estavam de acordo com a questão norteadora do estudo. No início da pesquisa obteve-se 3237 publicações, após a aplicação dos critérios de inclusão e exclusão totalizou-se parcialmente 89 artigos, depois de uma leitura mais precisa aderiu-se um total final de 15 publicações de acordo para serem trabalhadas na elaboração do referido estudo.

O fluxograma representado abaixo, caracteriza a estratégia de coleta de dados utilizada pelos autores, no sentido de detalhar as principais evidencias encontradas no estudo. 
Figura 2. Fluxograma Estratégia de Busca - Bases de Dados, Teresina-PI, Brasil, 2021.

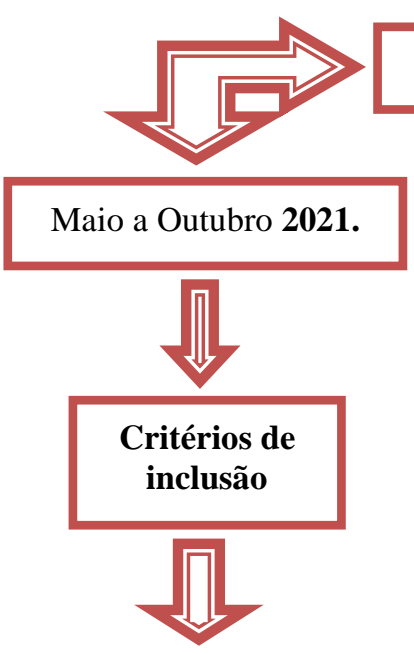

Artigos originais disponibilizados na íntegra, completos, que abrangessem a temática e na forma online, publicados nos idioma português, inglês e espanhol, publicações que respondiam a questão norteadora do estudo.

Estratégia de Busca Revisão Integrativa

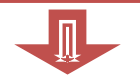

\section{Critérios de exclusão}

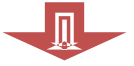

Artigos incompletos, artigos duplicados, teses, dissertações, monografias, manuais, $\mathrm{e}$ publicações que não estavam de acordo com a questão norteadora do estudo

de

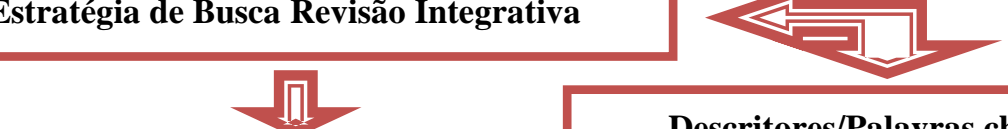

Descritores/Palavras chaves:
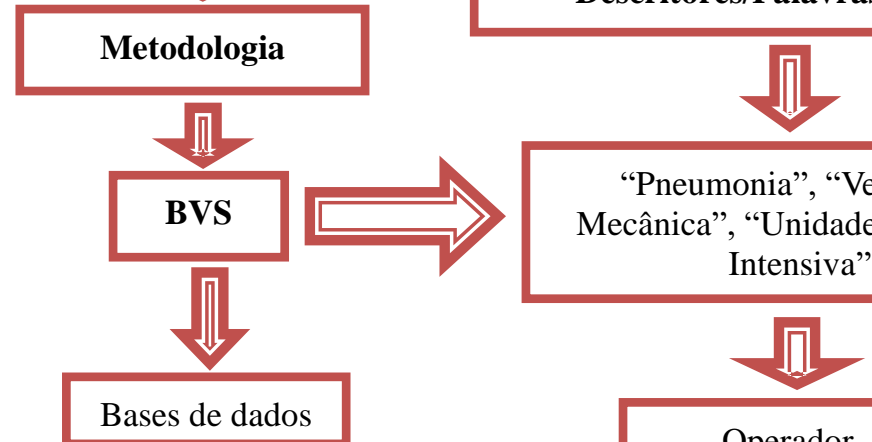

"Pneumonia", "Ventilação

Mecânica", "Unidade de Terapia Intensiva".

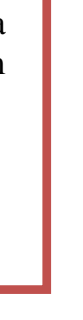




\section{Resultados e Discussão}

Diante dos resultados obtidos no estudo por meio da estratégia de busca, os autores delinearam variáveis para melhor descrever as evidências encontradas na pesquisa. O quadro a seguir caracteriza os artigos com base nas variáveis propostas: número do artigo, base de dados, periódico, autor e ano de publicação, tipo de estudo, título, objetivo, resultados em evidências e conclusões importantes.

Quadro 1. Caracterização dos artigos selecionados para o estudo.

\begin{tabular}{|c|c|c|c|c|c|c|c|}
\hline $\mathbf{N}$ & $\begin{array}{c}\text { Base de } \\
\text { Dados }\end{array}$ & Periódico & $\begin{array}{c}\text { Autor e } \\
\text { Ano }\end{array}$ & $\begin{array}{l}\text { Tipo de } \\
\text { Estudo }\end{array}$ & Título & Objetivo & $\begin{array}{c}\text { Resultados em evidências e conclusões } \\
\text { importantes }\end{array}$ \\
\hline 1 & LILACS & $\begin{array}{l}\text { Enferm. } \\
\text { Foco. }\end{array}$ & $\begin{array}{c}\text { Liz et al., } \\
2020 .\end{array}$ & $\begin{array}{c}\text { Estudo } \\
\text { descritivo, } \\
\text { qualitativo. }\end{array}$ & $\begin{array}{l}\text { Cuidados multi- } \\
\text { profissionais rela- } \\
\text { cionados a } \\
\text { prevenção da } \\
\text { pneumonia asso- } \\
\text { ciada à ventilação } \\
\text { mecânica. }\end{array}$ & $\begin{array}{l}\text { Conhecer a percepção da } \\
\text { equipe multiprofissional a } \\
\text { cerca dos } \\
\text { relacionados às medidas de } \\
\text { prevenção a pneumonia } \\
\text { associada à } \\
\text { mecânica. }\end{array}$ & $\begin{array}{l}\text { Dentre as práticas que auxiliam na prevenção da } \\
\text { PAV, verifica-se a execução dos rounds para } \\
\text { discussão dos casos, o uso de protocolos } \\
\text { assistenciais e as capacitações como importantes } \\
\text { ferramentas para o processo de trabalho com } \\
\text { vistas ao alcance dos melhores resultados. }\end{array}$ \\
\hline 2 & BDENF & $\begin{array}{l}\text { Rev } \\
\text { Enferm } \\
\text { UFPE } \\
\text { Online. }\end{array}$ & $\begin{array}{l}\text { França et } \\
\text { al., } 2021 .\end{array}$ & $\begin{array}{c}\text { Estudo } \\
\text { descritivo, } \\
\text { qualitativo. }\end{array}$ & $\begin{array}{l}\text { Cuidados de } \\
\text { enfermagem: } \\
\text { prevenção de } \\
\text { pneumonia asso- } \\
\text { ciada à ventilação } \\
\text { mecânica. }\end{array}$ & $\begin{array}{l}\text { Identificar os cuidados de } \\
\text { Enfermagem na prevenção } \\
\text { de pneumonia em } \\
\text { pacientes sob o uso de } \\
\text { ventilação } \text { mecânica } \\
\text { invasiva. }\end{array}$ & $\begin{array}{l}\text { As ações de Enfermagem para o controle da PAV } \\
\text { são de extrema importância dentro do contexto } \\
\text { terapêutico e de cuidado no hospital. Acrescenta- } \\
\text { se que a educação continuada e a adoção de } \\
\text { medidas baseadas em evidências científicas, bem } \\
\text { como protocolos em saúde, correspondem aos } \\
\text { melhoramentos dos aspectos em questão. }\end{array}$ \\
\hline 3 & BDENF & $\begin{array}{l}\text { Rev } \\
\text { Enferm } \\
\text { UFPE } \\
\text { Online. }\end{array}$ & $\begin{array}{c}\text { Alves } e t \\
\text { al., } 2021 .\end{array}$ & $\begin{array}{c}\text { Estudo } \\
\text { descritivo, } \\
\text { qualitativo. }\end{array}$ & $\begin{array}{l}\text { Pneumonia em } \\
\text { pacientes hospita- } \\
\text { lizados por traumas } \\
\text { sob tratamento } \\
\text { inten-sivo. }\end{array}$ & $\begin{array}{l}\text { Identificar os fatores de } \\
\text { risco e as formas de } \\
\text { prevenção da pneumonia } \\
\text { em pacientes hospitaliza- } \\
\text { dos por trauma em } \\
\text { Unidades de Terapia } \\
\text { Intensiva. }\end{array}$ & $\begin{array}{l}\text { Verifica-se que o desenvolvimento da PNM, } \\
\text { independentemente da sua categorização, } \\
\text { aumenta o tempo de permanência na UTI e de } \\
\text { hospitalização, eleva os custos dos serviços de } \\
\text { saúde e do tratamento e provoca uma lentificação } \\
\text { no processo de recuperação. }\end{array}$ \\
\hline 4 & LILACS & $\begin{array}{l}\text { Rev. } \\
\text { Epidemiolo } \\
\text { - gia. }\end{array}$ & $\begin{array}{l}\text { Maier, } \\
\text { Valim, } \\
\text { Santos, } \\
\text { Júnior, \& } \\
2020 .\end{array}$ & $\begin{array}{c}\text { Estudo } \\
\text { descritivo, } \\
\text { qualitativo. }\end{array}$ & $\begin{array}{c}\text { Pneumonia asso- } \\
\text { ciada à ventilação } \\
\text { mecânica: evidên- } \\
\text { cias científicas. }\end{array}$ & $\begin{array}{l}\text { Identificar os fatores } \\
\text { relacionados à prevenção } \\
\text { de pneumonia associada à } \\
\text { ventilação mecânica em } \\
\text { pacientes de unidades de } \\
\text { terapia intensiva. }\end{array}$ & $\begin{array}{l}\text { Destaca-se como intervenções comuns à } \\
\text { prevenção e esboçadas por grande parte dos } \\
\text { estudos: a extubação planejada de modo a evitar } \\
\text { a reintubação; a avaliação e redução da sedação } \\
\text { como parte do planejamento da extubação; a } \\
\text { aspiração oral e endotraqueal de forma asséptica, } \\
\text { antes da mudança de decúbito, em especial } \\
\text { quando não houver mensuração rotineira da } \\
\text { pressão do cuff; a manutenção da cabeceira } \\
\text { elevada entre } 30^{\circ} \text { e } 45^{\circ} \text {; a higiene oral com } \\
\text { clorexidina de } 0,12 \% \text { a } 2 \% \text {; e o reprocessamento } \\
\text { por esterilização dos circuitos ventilatórios ou a } \\
\text { utilização de circuitos de uso único. }\end{array}$ \\
\hline 5 & LILACS & $\begin{array}{c}\text { Revista } \\
\text { Cuidarte } \\
\text { Enero. }\end{array}$ & $\begin{array}{l}\text { Maran et } \\
\text { al., } 2020 .\end{array}$ & $\begin{array}{c}\text { Estudo } \\
\text { descritivo, } \\
\text { qualitativo. }\end{array}$ & $\begin{array}{l}\text { Efeitos da utilização } \\
\text { do bundle na } \\
\text { prevenção de } \\
\text { pneumonia asso- } \\
\text { ciada à ventilação } \\
\text { mecânica. }\end{array}$ & $\begin{array}{l}\text { Identificar na literatura } \\
\text { científica os efeitos do uso } \\
\text { de Bundles na prevenção } \\
\text { da pneumonia associada à } \\
\text { ventilação mecânica em } \\
\text { unidade de terapia } \\
\text { intensiva. }\end{array}$ & $\begin{array}{l}\text { O uso do Bundle na prevenção da PAV em UTI } \\
\text { tem efeitos positivos, pois estudos desenvolvidos } \\
\text { em diferentes países constataram que a adesão a } \\
\text { essa ferramenta de segurança resultou em } \\
\text { redução na taxa de PAV, na mortalidade de } \\
\text { pacientes, no seu tempo de internação e também; } \\
\text { nos custos hospitalares. }\end{array}$ \\
\hline 6 & SCIELO & $\begin{array}{c}\text { Cuid } \\
\text { Enferm. }\end{array}$ & $\begin{array}{l}\text { Montini } \\
\text { et al., } \\
2020 .\end{array}$ & $\begin{array}{l}\text { Estudo } \\
\text { transversal, } \\
\text { descritivo, } \\
\text { quantitativo } \\
\text {, analítico. }\end{array}$ & $\begin{array}{c}\text { Adesão ao bundle } \\
\text { para prevenção de } \\
\text { pneumonia asso- } \\
\text { ciada à ventilação } \\
\text { mecânica em terapia } \\
\text { intensiva. }\end{array}$ & $\begin{array}{l}\text { Verificar adesão ao bundle } \\
\text { de pneumonia associada à } \\
\text { ventilação mecânica em } \\
\text { terapia intensiva. }\end{array}$ & $\begin{array}{l}\text { Acredita-se que o acompanhamento dos índices } \\
\text { de PAV seja importante por ser um dos } \\
\text { indicadores de qualidade do atendimento } \\
\text { prestado em serviços de saúde. Portanto, } \\
\text { investigar o conhecimento e atitude dos } \\
\text { profissionais que atuam nas UTIs sobre a } \\
\text { aplicação do bundle de prevenção de PAV pode } \\
\text { contribuir para melhor conhecimento e redução } \\
\text { dos índices, visto que intervenções devem ser } \\
\text { planejadas junto à equipe, buscando melhoria das } \\
\text { práticas multiprofissionais de cuidado ao } \\
\text { paciente crítico. }\end{array}$ \\
\hline & & & & & & & \\
\hline
\end{tabular}




\begin{tabular}{|c|c|c|c|c|c|c|c|}
\hline 7 & BDENF & $\begin{array}{l}\text { Rev } \\
\text { Enferm } \\
\text { UFPE } \\
\text { Online. }\end{array}$ & $\begin{array}{c}\text { Dutra et } \\
\text { al., } 2019 .\end{array}$ & $\begin{array}{c}\text { Estudo } \\
\text { qualitativo, } \\
\text { descritiva e } \\
\text { exploratória }\end{array}$ & $\begin{array}{l}\text { Apreender a } \\
\text { percepção dos } \\
\text { profissionais de } \\
\text { Enfermagem so-bre } \\
\text { a segurança do } \\
\text { paciente sob } \\
\text { ventilação mecâ- } \\
\text { nica com vistas à } \\
\text { prevenção da PAV. }\end{array}$ & $\begin{array}{l}\text { Pneumonia associada à } \\
\text { ventilação mecânica: } \\
\text { percepção dos profissionais } \\
\text { de enfermagem. }\end{array}$ & $\begin{array}{l}\text { Destaca-se o tempo de intubação e de ventilação } \\
\text { mecânica, as microaspirações a partir da } \\
\text { colonização da orofaringe, a aspiração } \\
\text { inadequada de vias aéreas e do tubo orotraqueal, } \\
\text { o uso de sondas para suporte nutricional e os } \\
\text { cuidados indevidos com equipamentos como } \\
\text { fatores capazes de comprometer a segurança do } \\
\text { paciente mecanicamente ventilado e, a partir } \\
\text { desta percepção, executam-se medidas } \\
\text { preventivas, sendo a aspiração de vias aéreas a } \\
\text { medida predominante nos depoimentos dos } \\
\text { profissionais. }\end{array}$ \\
\hline 8 & LILACS & $\begin{array}{l}\text { J. Res. } \\
\text { Fundam. } \\
\text { Care. } \\
\text { Online. }\end{array}$ & $\begin{array}{l}\text { Melo, } \\
\text { Santiago, } \\
\text { Nogueira } \\
\quad, \& \\
\text { Vasconce } \\
\text { los, } 2019 .\end{array}$ & $\begin{array}{l}\text { Estudo } \\
\text { transversal, } \\
\text { quanti- } \\
\text { qualitativo. }\end{array}$ & $\begin{array}{l}\text { Pneumonia asso- } \\
\text { ciada à ventilação } \\
\text { mecânica: conhe- } \\
\text { cimento dos } \\
\text { profissionais de } \\
\text { saúde acerca da } \\
\text { prevenção e medidas } \\
\text { educativas. }\end{array}$ & 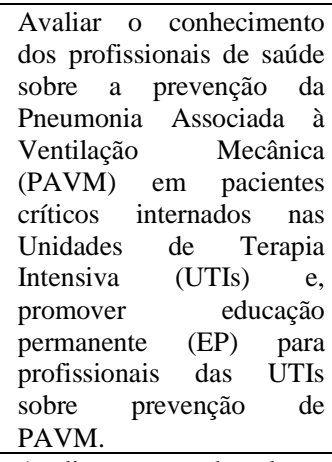 & $\begin{array}{l}\text { A adesão dos processos de educação permanente } \\
\text { pelos profissionais é um dos focos dos hospitais } \\
\text { de ensino, por ser uma forma de auxiliar no } \\
\text { gerenciamento de riscos, na melhoria da } \\
\text { assistência e, consequentemente, na redução de } \\
\text { taxas de infecções hospitalares. Assim, as } \\
\text { equipes das UTIs precisam estar conectadas e } \\
\text { dispostas a construir e aderir protocolos } \\
\text { assistenciais ou bundles (pacote de cuidados) de } \\
\text { prevenção de pneumonia associada à ventilação } \\
\text { mecânica. }\end{array}$ \\
\hline 9 & LILACS & $\begin{array}{l}\text { Rev. } \\
\text { Epidemiol. } \\
\text { Controle } \\
\text { Infecç. }\end{array}$ & $\begin{array}{l}\text { Lourenço } \\
\text { ne, } \\
\text { Branco, } \\
\text { Monteiro } \\
\text { Fonseca, } \\
2019 .\end{array}$ & $\begin{array}{c}\text { Estudo } \\
\text { observacion } \\
\text { al, } \\
\text { longitudinal }\end{array}$ & $\begin{array}{l}\text { Adesão às medidas } \\
\text { preventivas versus } \\
\text { incidência de } \\
\text { pneumonia asso- } \\
\text { ciada à ventilação } \\
\text { mecânica. }\end{array}$ & $\begin{array}{l}\text { Avaliar a taxa de adesão } \\
\text { das ações preventivas da } \\
\text { equipe de enfermagem } \\
\text { para PAV após a } \\
\text { reestruturação e aplicação } \\
\text { do protocolo de prevenção } \\
\text { e verificar as taxas de } \\
\text { densidade de incidência de } \\
\text { pacientes com PAV. }\end{array}$ & $\begin{array}{l}\text { Após a reestruturação do protocolo de prevenção } \\
\text { da PAV, em seis meses de monitorização, a } \\
\text { vigilância e o reforço contínuo da equipe de } \\
\text { enfermagem para a realização das medidas } \\
\text { preventivas alcançaram índices de adesão acima } \\
\text { dos } 77 \% \text {, simultaneamente à diminuição nos de } \\
\text { PAV. }\end{array}$ \\
\hline 10 & LILACS & $\begin{array}{l}\text { Rev. } \\
\text { Epidemiol. } \\
\text { Controle } \\
\text { Infecç. }\end{array}$ & $\begin{array}{l}\text { Brentini } \\
\text { et al., } \\
2019 .\end{array}$ & $\begin{array}{l}\text { Estudo } \\
\text { descritivo, } \\
\text { transversal, } \\
\text { retrospectiv } \\
\quad \text { o, } \\
\text { quantitativo } \\
\quad \text {. }\end{array}$ & $\begin{array}{l}\text { Incidência de } \\
\text { pneumonia asso- } \\
\text { ciada à ventilação } \\
\text { mecâ-nica de os } \\
\text { agentes etiológi-cos } \\
\text { mais prevalentes em } \\
\text { uma unidade de } \\
\text { terapia intensiva no } \\
\text { interior de São } \\
\text { Paulo. }\end{array}$ & $\begin{array}{l}\text { Analisar a taxa e densidade } \\
\text { de incidência da } \\
\text { pneumonia associada à } \\
\text { ventilação mecânica e os } \\
\text { agentes etiológicos mais } \\
\text { prevalentes na cultura de } \\
\text { secreção traqueal em uma } \\
\text { unidade de terapia } \\
\text { intensiva adulto. }\end{array}$ & $\begin{array}{l}\text { A taxa e a densidade de incidência da pneumonia } \\
\text { associada à ventilação mecânica apresentaram } \\
\text { aumento não esperado em três meses } \\
\text { consecutivos no período do estudo. A vigilância } \\
\text { em tempo real e a detecção de oscilações da } \\
\text { incidência de infecção devem ser valorizadas } \\
\text { para ajustes nas estratégias setoriais para } \\
\text { promover a proteção à saúde dos indivíduos em } \\
\text { tratamento. }\end{array}$ \\
\hline 11 & BDENF & $\begin{array}{l}\text { Rev } \\
\text { Enferm } \\
\text { UFPE } \\
\text { Online. }\end{array}$ & $\begin{array}{l}\text { Santos et } \\
\text { al., } 2018 .\end{array}$ & $\begin{array}{c}\text { Estudo } \\
\text { descritivo, } \\
\text { qualitativo. }\end{array}$ & $\begin{array}{l}\text { Fatores de risco que } \\
\text { favorecem a } \\
\text { pneumonia asso- } \\
\text { ciada à ventilação } \\
\text { mecânica. }\end{array}$ & $\begin{array}{llr}\text { Analisar os } & \text { principais } \\
\text { fatores de } & \text { risco que } \\
\text { favorecem à } & \text { pneumonia } \\
\text { associada } & \text { à } & \text { ventilação } \\
\text { mecânica. } & & \end{array}$ & $\begin{array}{l}\text { Revela-se que, em meio aos principais fatores de } \\
\text { risco para a ocorrência do problema, os mais } \\
\text { relevantes são as práticas incorretas de higiene } \\
\text { realizadas pela equipe de saúde tendo em vista a } \\
\text { existência de muitos patógenos oportunistas e } \\
\text { que facilmente poderiam ser eliminados por meio } \\
\text { de uma higiene eficaz. }\end{array}$ \\
\hline 12 & LILACS & $\begin{array}{l}\text { Arq. } \\
\text { Catarin } \\
\text { Med. }\end{array}$ & $\begin{array}{l}\text { Kock, } \\
\text { Rosa, } \\
\text { Martigna } \\
\text { go, \& } \\
\text { Maurici, } \\
2017 .\end{array}$ & $\begin{array}{l}\text { Estudo de } \\
\text { coorte } \\
\text { prospectivo }\end{array}$ & $\begin{array}{l}\text { Pneumonia asso- } \\
\text { ciada à ventilação } \\
\text { mecâni ca (pavm): } \\
\text { incidência e } \\
\text { desfecho clínico em } \\
\text { uma Unidade de } \\
\text { Terapia Intensiva no } \\
\text { sul de Santa } \\
\text { Catarina. }\end{array}$ & $\begin{array}{lr}\text { Apontar o diagnóstico de } \\
\text { internação, identificar a } \\
\text { incidência de PAVM e } \\
\text { descrever o tempo de } \\
\text { internação, tempo de } \\
\text { ventilação mecânica e } \\
\text { mortalidade dos pacientes } \\
\text { ventilados mecanicamente } \\
\text { da UTI do Hospital Nossa } \\
\text { Senhora da Conceição } \\
\text { (HNSC), Tubarão - SC. }\end{array}$ & $\begin{array}{l}\text { A PAVM é uma entidade clínica de difícil } \\
\text { diagnóstico, possuindo como critérios } \\
\text { obrigatórios: hipertermia ou hipotermia, } \\
\text { leucocitose ou leucopenia, alteração na } \\
\text { quantidade ou qualidade do escarro, e infiltrado } \\
\text { novo ou persistente no raio } X \text { de tórax. A } \\
\text { identificação do agente etiológico apresenta-se } \\
\text { como critério opcional, podendo ser obtida por } \\
\text { lavado broncoalveolar, escovado protegido ou } \\
\text { aspirado traqueal. }\end{array}$ \\
\hline 13 & LILACS & $\begin{array}{l}\text { Ciência \& } \\
\text { Saúde } \\
\text { Coletiva. }\end{array}$ & $\begin{array}{c}\text { Pombo, } \\
\text { Almeida, } \\
\& \\
\text { Rodrigue } \\
\text { s, } 2010 .\end{array}$ & $\begin{array}{c}\text { Estudo } \\
\text { descritivo } \\
\text { quantitativo } \\
\end{array}$ & $\begin{array}{l}\text { Conhecimento dos } \\
\text { profissionais de } \\
\text { saúde na Unidade de } \\
\text { Terapia Intensiva } \\
\text { sobre prevenção de } \\
\text { pneumonia asso- } \\
\text { ciada à ventilação } \\
\text { mecânica. }\end{array}$ & $\begin{array}{l}\text { Avaliar o conhecimento } \\
\text { dos profissionais de saúde } \\
\text { sobre a prevenção da } \\
\text { PAVM em duas UTI de } \\
\text { dois hospitais públicos de } \\
\text { Fortaleza (CE). }\end{array}$ & $\begin{array}{l}\text { O conhecimento sobre a PAVM e fatores de risco } \\
\text { a ela associada é apenas regular. Sugerimos e } \\
\text { reforçamos, em um segundo momento, a } \\
\text { elaboração de uma proposta educativa que } \\
\text { norteie a atuação dos profissionais de saúde das } \\
\text { UTI e que contemple as estratégias necessárias } \\
\text { para prevenção da PAVM, pois só através do } \\
\text { conhecimento teórico e prático é que os } \\
\text { profissionais tomarão consciência de seu } \\
\text { papel na tomada de decisão e execução do plano } \\
\text { de ações para redução e controle da doença. }\end{array}$ \\
\hline
\end{tabular}




\begin{tabular}{|c|c|c|c|c|c|c|c|}
\hline 14 & LILACS & $\begin{array}{c}\text { Esc Anna } \\
\text { Nery. }\end{array}$ & $\begin{array}{l}\text { Gonçalve } \\
\text { s et al., } \\
2012 \text {. }\end{array}$ & $\begin{array}{c}\text { Ensaio } \\
\text { clínico } \\
\text { controlado } \\
\text { não } \\
\text { randomizad } \\
\text { o. }\end{array}$ & $\begin{array}{c}\text { Eficácia de } \\
\text { estratégias educa- } \\
\text { tivas para ações } \\
\text { preventivas da } \\
\text { pneumonia asso- } \\
\text { ciada à ventilação } \\
\text { mecânica. }\end{array}$ & $\begin{array}{l}\text { Determinar a eficácia de } \\
\text { estratégia educativa para } \\
\text { melhorar o desempenho da } \\
\text { equipe de enfermagem na } \\
\text { realização } \\
\text { procedimentos }\end{array}$ & $\begin{array}{l}\text { Os fatores de risco podem ser reduzidos com } \\
\text { medidas centradas em ações da equipe que } \\
\text { assiste o indivíduo sob VM, como a higienização } \\
\text { das mãos dos PAS, a implantação de protocolos } \\
\text { que estimulem o uso racional de antimicrobianos, } \\
\text { a interrupção diária da sedação, o desmame } \\
\text { ventilatório e, ainda, estratégias que visam à } \\
\text { redução de procedimentos invasivos na Unidade } \\
\text { de Terapia Intensiva (UTI). }\end{array}$ \\
\hline 15 & LILACS & $\begin{array}{c}\text { J Bras } \\
\text { Pneumol. }\end{array}$ & $\begin{array}{l}\text { Rodrigue } \\
\text { s, Neto, } \\
\text { Santos, \& } \\
\text { Knibel, } \\
2009 .\end{array}$ & $\begin{array}{l}\text { Estudo de } \\
\text { coorte } \\
\text { prospectivo }\end{array}$ & $\begin{array}{c}\text { Pneumonia asso- } \\
\text { ciada à ventilação } \\
\text { mecânica: epide- } \\
\text { miologia e impacto } \\
\text { na evolução clínica } \\
\text { de pacientes em uma } \\
\text { unidade de terapia } \\
\text { intensiva. }\end{array}$ & $\begin{array}{l}\text { Avaliar o impacto dessa } \\
\text { doença na evolução clínica } \\
\text { dos pacientes. }\end{array}$ & $\begin{array}{l}\text { A pneumonia é a principal causa de infecção } \\
\text { nosocomial em UTIs, ocorrendo, em mais de } \\
90 \% \text { dos casos, em pacientes submetidos à } \\
\text { intubação endotraqueal e ventilação mecânica } \\
\text { (VM). Devido a sua relevância clínica e seu } \\
\text { perfil epidemiológico, a pneumonia associada à } \\
\text { ventilação mecânica (PAVM) é estudada como } \\
\text { uma entidade clínica distinta dentro das } \\
\text { pneumonias nosocomiais, representando um dos } \\
\text { principais desafios enfrentados pelo intensivista } \\
\text { em sua prática diária. }\end{array}$ \\
\hline
\end{tabular}

Fonte: Autores (2021).

No Quadro 1, tem-se a apresentação dos artigos selecionados para o estudo conforme número do artigo, base de dados, periódico, autor e ano de publicação, tipo de estudo, título, objetivo, resultados em evidências e conclusões importantes, com a finalidade de facilitar o desenvolvimento da discussão. A partir do estudo dos artigos estabeleceram-se discussões relevantes para observações das produções científicas relacionadas à pesquisa.

No gráfico a seguir, estão expostos os periódicos e a quantidade de artigos encontrados na seleção da amostra final dos artigos que são trabalhados na elaboração do referido estudo.

Gráfico 1. Distribuição dos artigos conforme periódico e quantidade e quantidade de artigos.

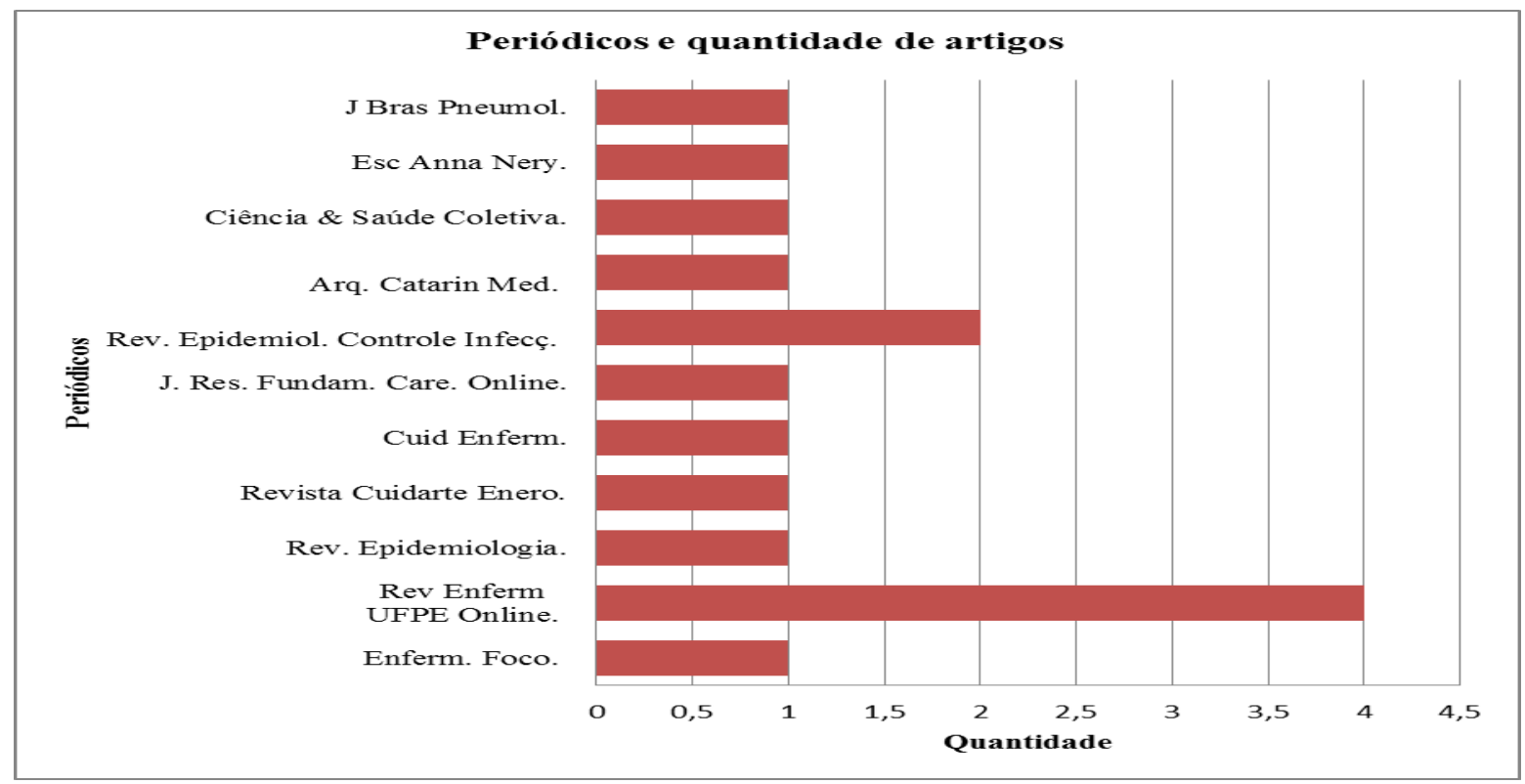

Fonte: Autores (2021).

Segundo o gráfico ilustrado acima, pode-se observar os periódicos e a quantidade de artigos que foram publicados de acordo com a amostra final do referido estudo. Dessa forma, verifica-se que na J Bras Pneumol (1) publicação, Esc Anna Nery (1), Ciência \& Saúde Coletiva (1), Arq Catarin Med (1), Rev Enferm UFPE Online (4), Rev Epidemiol Controle Infecç (2), J Rer Fundam Care Online (1), Cuid Enferm (1), Rev Cuidaste Enero (1), Rev Epidemiologia (1), Enferm Foco (1). Assim, totalizando 15 artigos para serem trabalhados na elaboração do presente estudo. 
Gráfico 2. Distribuição dos artigos de acordo com o periódico e a porcentagem.

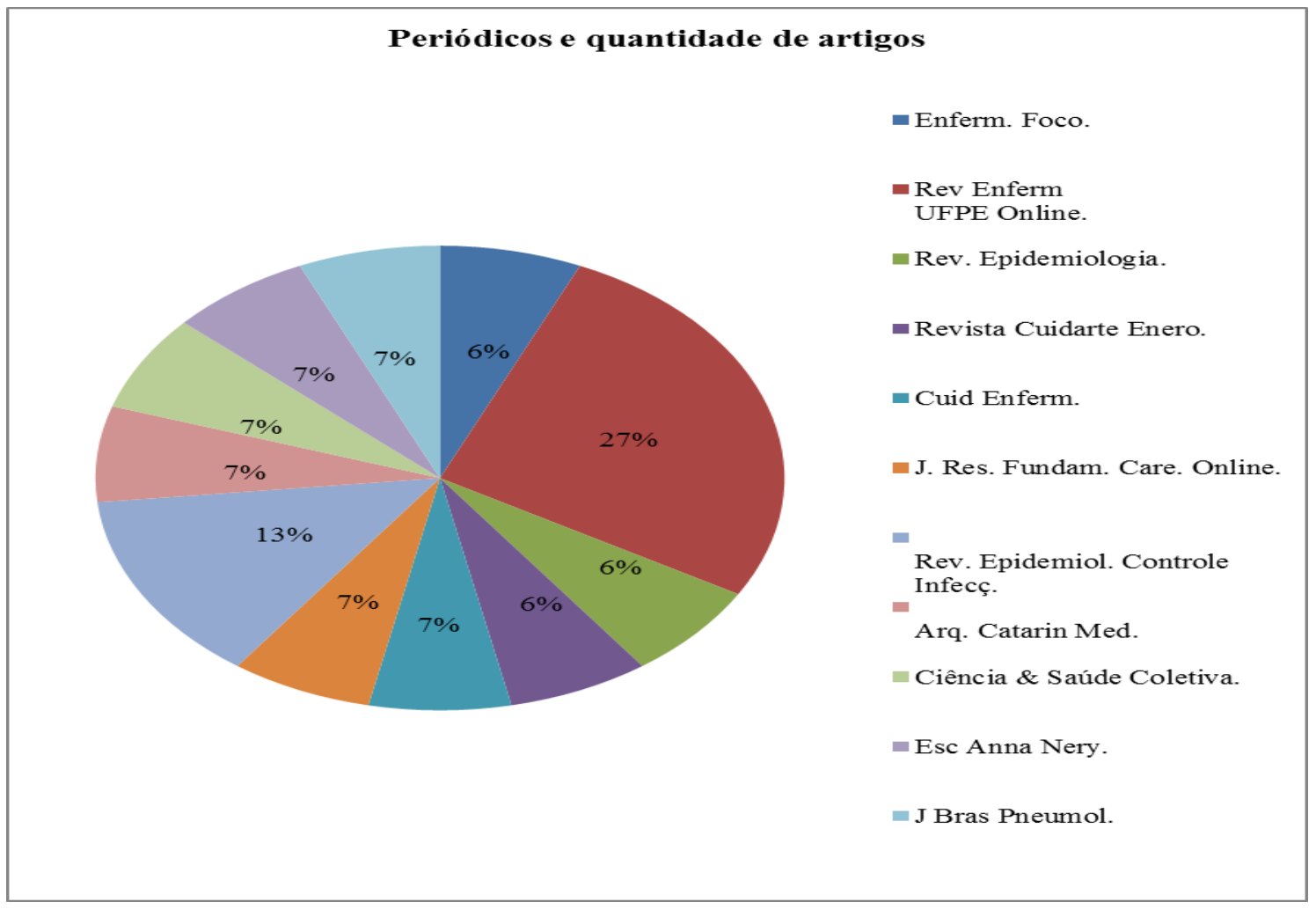

Fonte: Autores (2021).

De acordo, com o gráfico ilustrado acima, pode-se observar os periódicos e a porcentagem de artigos que foram publicados de acordo com a amostra final do referente estudo. Dessa forma, verifica-se que na $\mathrm{J}$ Bras Pneumol (7\%) das publicações, Esc Anna Nery (7\%), Ciência \& Saúde Coletiva (7\%), Arq Catarin Med (7\%), Rev Enferm UFPE Online (27\%), Rev Epidemiol Controle Infecç (13\%), J Rer Fundam Care Online (7\%), Cuid Enferm (7\%), Rev Cuidaste Enero (6\%), Rev Epidemiologia (6\%), Enferm Foco (6\%). Assim, totalizando 15 artigos para serem trabalhados na elaboração do presente estudo.

Gráfico 3. Distribuição dos artigos conforme os anos de publicação e quantidade.

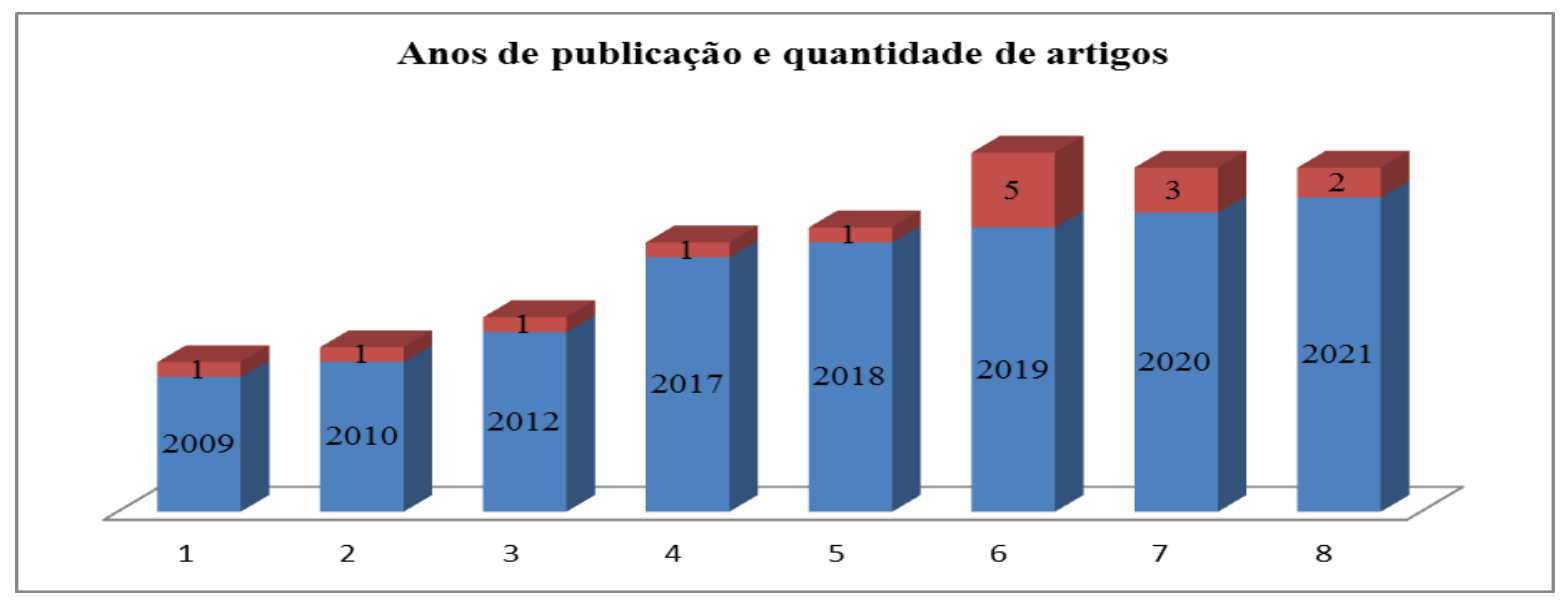

Fonte: Autores (2021). 
Ao analisar o gráfico representado acima, observa-se os anos de publicação e a quantidade de artigos publicados, nota-se que no ano de 2009 (1) publicação, 2010 (1), 2012 (1), 2017 (1), 2018 (1), 2019 (5), 2020 (3), 2021 (2). Assim, totalizando 15 artigos publicados e selecionados para serem utilizados na elaboração do presente estudo.

Gráfico 4. Distribuição dos anos de publicação e porcetagem.

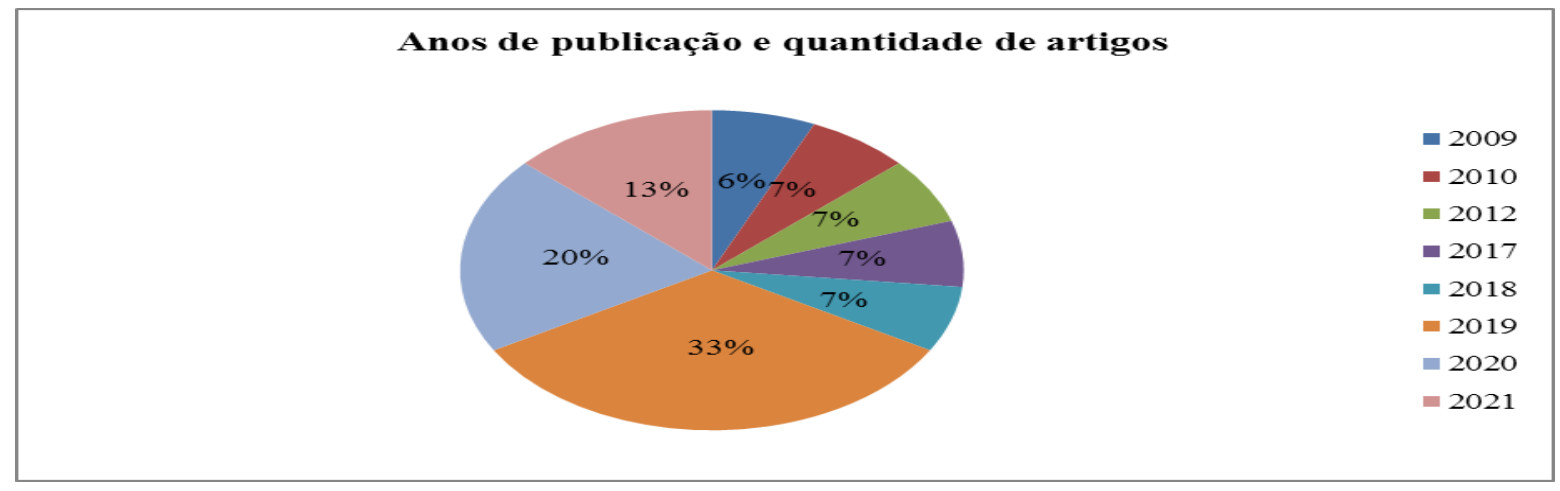

Fonte: Autores (2021).

Ao verificar o gráfico acima, percebe-se os anos de publicação e porcentagem dos artigos publicados de acordo com cada ano, identifica-se que no ano de 2009 (6\%) publicação, 2010 (7\%), 2012 (7\%), 2017 (7\%), 2018 (7\%), 2019 (33\%), 2020 (20\%), 2021 (13\%). Totalizando 100\% das publicações, escolhidas para compor a construção do referido estudo.

Gráfico 5. Distribuição dos artigos conforme os tipos de estudo e quantidade.

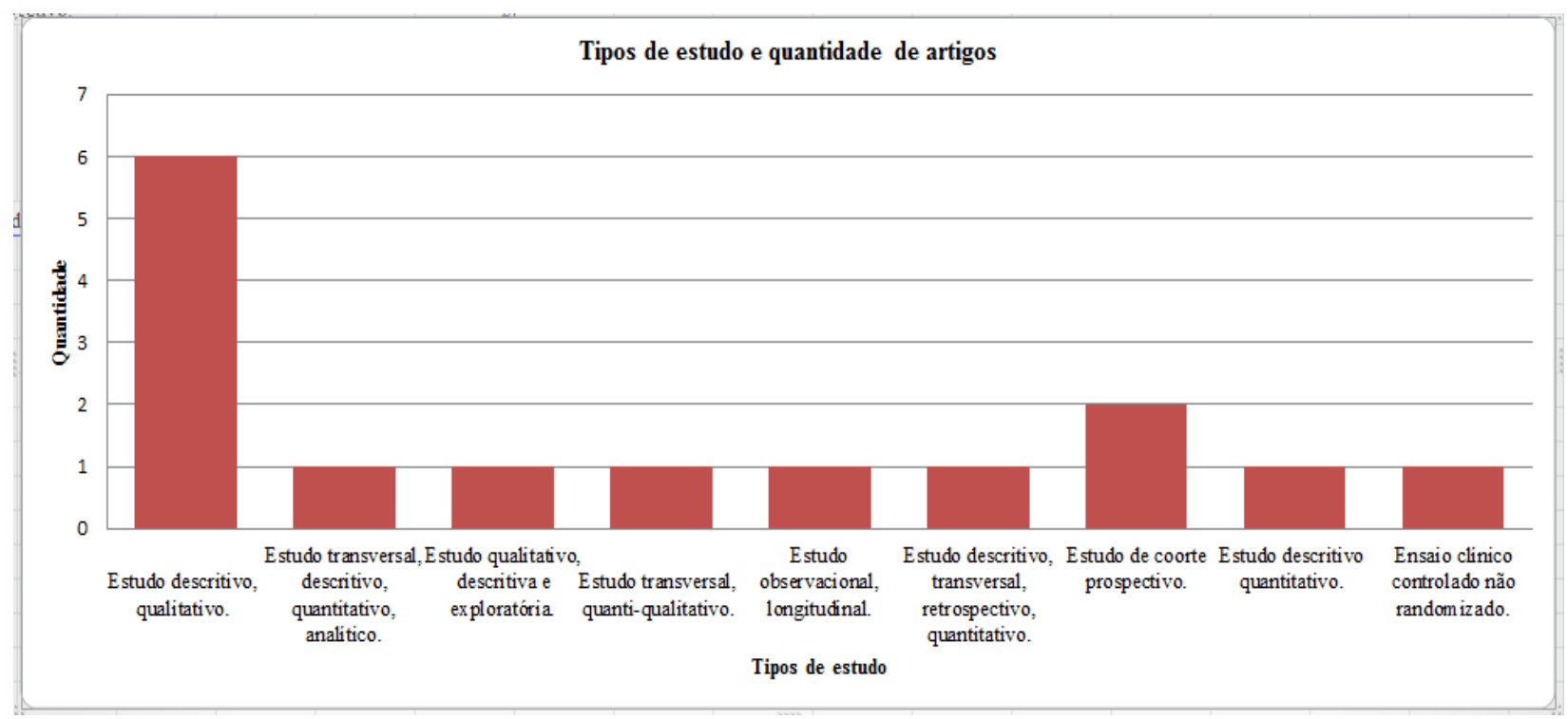

Fonte: Autores (2021).

Ao analisar o gráfico representado acima, identificam-se os tipos de estudo e a quantidade de artigos publicados. Nota-se que, evidenciou-se um total de: estudo descritivo, qualitativo (6), estudo transversal, descritivo, quantitativo analítico (1), estudo qualitativo, descritivo e exploratório (1), estudo transversal quanti-qualitativo (1), estudo observacional, longitudinal (1), estudo descritivo, transversal, retrospectivo, quantitativo (1), estudo de coorte prospectivo (2), estudo descritivo quantitativo (1), ensaio clínico controlado não randomizado (1). Totalizando 15 estudos selecionados na amostra final para construção do presente estudo. 
Gráfico 6. Distribuição dos artigos conforme tipos de estudo e porcentagem.

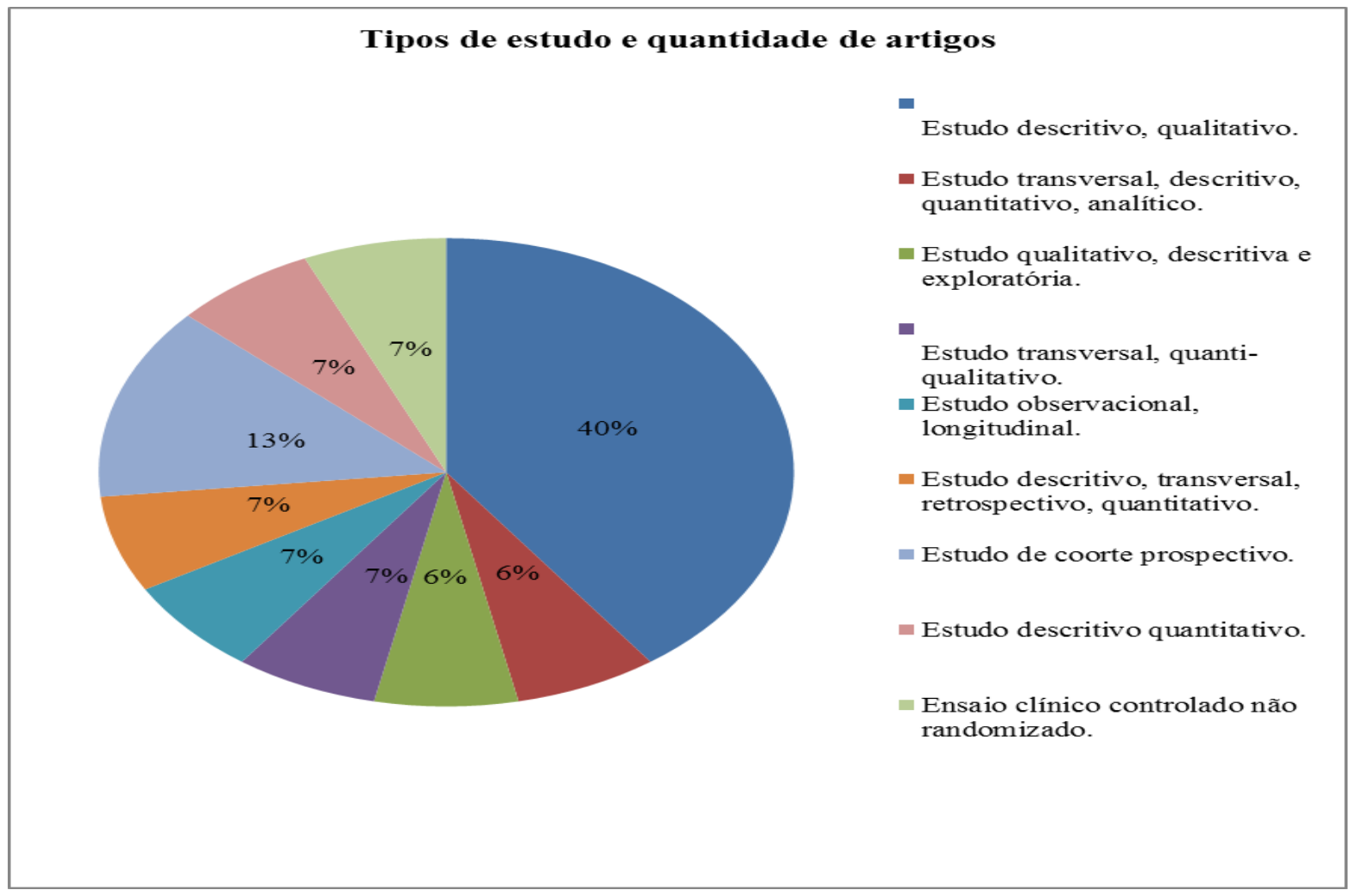

Fonte: Autores (2021).

Ao analisar o gráfico representado acima, percebe-se os tipos de estudos e a porcentagem de cada um respectivamente: estudo descritivo, qualitativo (40\%), estudo transversal, descritivo, quantitativo analítico (6\%), estudo qualitativo, descritivo e exploratório (6\%), estudo transversal quanti-qualitativo (7\%), estudo observacional, longitudinal (7\%), estudo descritivo, transversal, retrospectivo, quantitativo (7\%), estudo de coorte prospectivo (13\%), estudo descritivo quantitativo (7\%), ensaio clínico controlado não randomizado (7\%). Totalizando um resultado de $100 \%$ das publicações.

Gráfico 7. Distribuição dos artigos de acordo com as bases de dados e a quantidade de artigos.

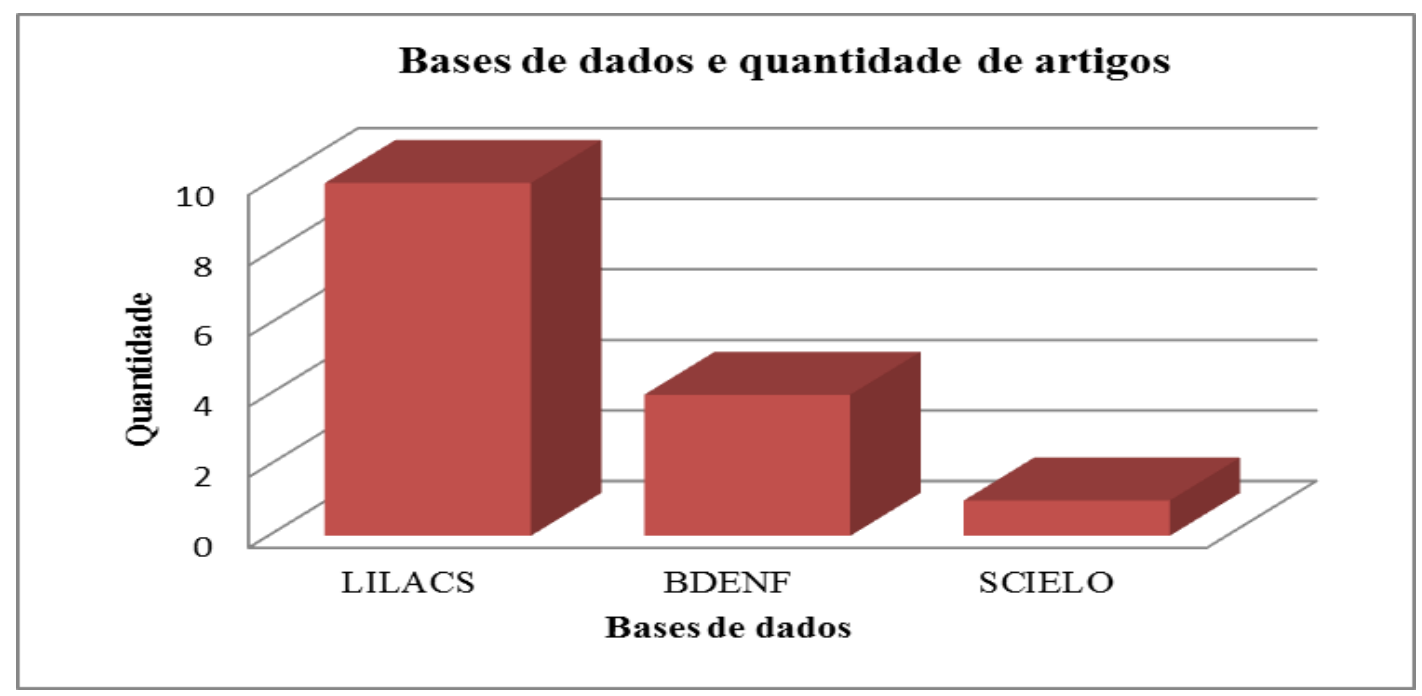

Fonte: Autores (2021). 
Segundo o gráfico representado acima é possível identificar as bases de dados e a quantidade de artigo publicados em cada uma. Nota - se que na Literatura Latino-Americana e do Caribe em Ciências da Saúde (LILACS) ocorreu (10) publicações, Base de Dados de Enfermagem (BDENF), (4) e - Scientific Electronic Library Online (SCIELO) (1). Sendo que foram adotados os critérios metodológicos na elaboração do referido estudo.

Gráfico 8. Distribuição dos artigos de acordo com as bases de dados e a porcentagem de artigos.

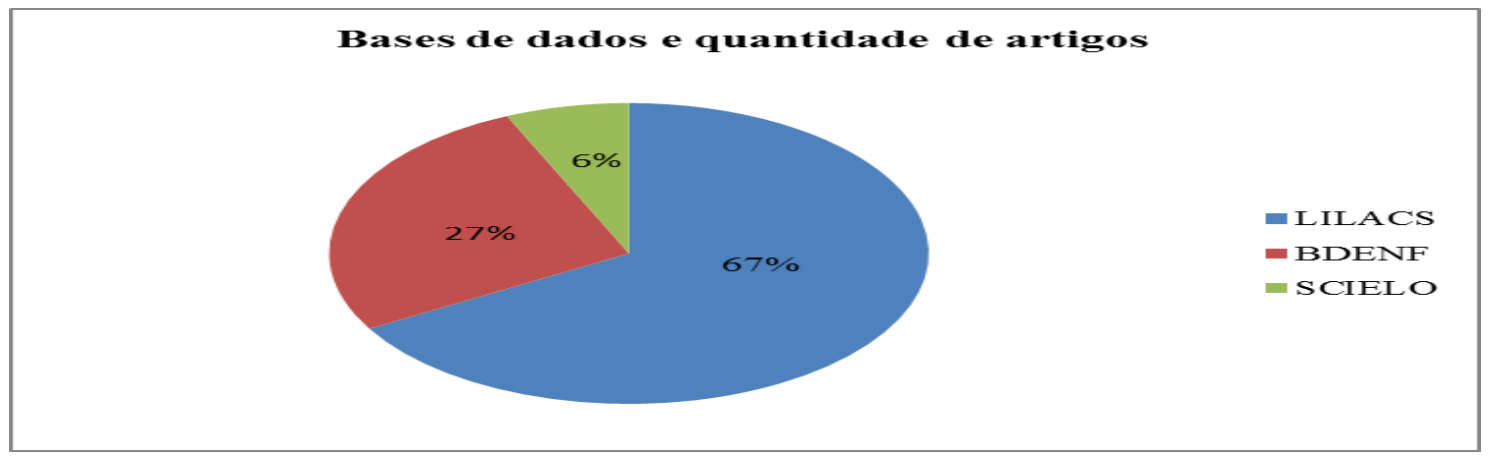

Fonte: Autores (2021).

De acordo com o gráfico ilustrado acima identifica-se as bases de dados e a porcentagem dos artigo publicados em cada uma. Nota - se que na Literatura Latino-Americana e do Caribe em Ciências da Saúde (LILACS) ocorreu (67\%) das publicações, Base de Dados de Enfermagem (BDENF), (27\%) e - Scientific Electronic Library Online (SCIELO) (6\%). Sendo que foram adotados os critérios metodológicos na elaboração do presente estudo.

A Pneumonia associada à ventilação mecânica (PAV) é a infecção que ocorre 48 horas após a intubação e/ou 72 horas após a extubação, cujos agentes etiológicos não estavam presentes no período da admissão do paciente. Surge como uma infecção que comumente acomete pacientes críticos ventilados mecanicamente na Unidade de Terapia Intensiva (UTI). Assim, dados epidemiológicos evidenciam que PAV apresenta incidência entre 10 e 30\% do total de pacientes internados na UTI. Ainda, está associada à hospitalização prolongada, aumento dos custos com cuidados de saúde e mortalidade de 8,1\% a 31,9\%, representando um desafio terapêutico (Liz et al., 2020).

Sob esta perspectiva do trabalho realizado junto à equipe multiprofissional, percebeu-se que, para todos os participantes, a enfermagem influencia na realização dos cuidados focados na prevenção de PAV, uma vez que o maior contato com os pacientes é da equipe de enfermagem, ou seja, a enfermagem tem participação essencial nos processos que se destinam a garantir e melhorar a qualidade da assistência prestada e, explorando mais amiúde a atuação do enfermeiro especificamente, percebemos que está intimamente ligada ao controle e supervisão das práticas preventivas, sendo estas consideradas um meio para manter a qualidade da assistência prestada (Liz et al., 2020).

Nesse sentido, o enfermeiro quando planeja, executa, delega, capacita sua equipe, educa o usuário, articula-se com outros profissionais e quando ele prevê e provê recursos sejam humanos ou manterias, ele está participando ativamente do cuidado. Neste sentido, o enfermeiro representa um dos profissionais que mais se responsabiliza pela organização do ambiente, a partir da competência que tem para introduzir técnicas que assegurem, a redução das agressões microbianas e, por ter um convívio direto e rotineiro com os pacientes, desempenha um papel fundamental na prevenção e controle desses eventos (Liz et al., 2020).

Segundo Maier et al., (2020), os principais fatores de risco desencadeadores da PAV apontados são: tempo de ventilação mecânica superior a cinco dias, levando ao uso de traqueostomia; extubação não planejada, que pode culminar em 
reintubação; dieta por sonda nasoenteral com posicionamento gástrico, aliada à não utilização da cabeceira elevada de $30^{\circ}$ a $45^{\circ}$; e uso de antibioticoterapia prévia, com a combinação de três ou mais antimicrobianos.

De acordo Pombo et al., (2010), com os fatores de risco da PAVM são idade avançada acima de setenta anos; coma; nível de consciência; intubação e reintubação traqueal; condições imunitárias; uso de drogas imunodepressoras; choque; gravidade da doença; antecedência de Doença Pulmonar Obstrutiva Crônica (DPOC); tempo prolongado de ventilação mecânica maior que sete dias; aspirado do condensado contaminado dos circuitos do ventilador; desnutrição; contaminação exógena; antibioticoterapia como profilaxia; colonização microbiana; cirurgias prolongadas; aspiração de secreções contaminadas; colonização gástrica e aspiração desta, o pH gástrico (maior que 4). O conhecimento dos fatores de risco para PAVM é de fundamental importância para interferir na cadeia epidemiológica e na tomada de decisão do controle e prevenção da doença.

O profissional de enfermagem tem como competência alguns procedimentos inteiramente ligados com o cuidado, principalmente, dos cuidados preventivos dos incidentes associados à contaminação, como, por exemplo, a monitorização da pressão do cuff (balonete), a realização e a avaliação da necessidade de aspiração das vias aéreas nos pacientes sob ventilação mecânica, a realização e/ou prescrição de higiene bucal. Criou-se, pelo Institute for Healthcare Improvement (IHI), o Bundle de Ventilação, em que são instituídas medidas para a prevenção da PAV baseadas em evidências científicas. Relaciona-se a implementação de tais medidas à diminuição da incidência de PAV, sendo de grande relevância a implementação do Bundle de Ventilação durante a assistência de Enfermagem em UTIs (França et al., 2021).

Demonstra-se, pela implementação de medidas durante a assistência de Enfermagem em UTIs, diminuição da incidência de PAV nos pacientes em uso de ventilação mecânica e, quando implementadas em conjunto, essas resultaram em melhorias substanciais na assistência em saúde nas instituições trazidas pelos estudos. Apontam-se como medidas de intervenções nos estudos: cabeceira elevada com angulação mínima de $30^{\circ}$ e máxima de $45^{\circ}$; manutenção do circuito ventilatório sem sujidade visível, com garantia de esterilização dos circuitos reprocessáveis; manutenção da pressão do cuff entre 20 e 30 cmH2O; uso de clorexidina $0,12 \%$ na higiene oral, no mínimo três vezes ao dia; higiene oral utilizando apenas solução salina e higienização das mãos antes e após contato e manipulação das vias aéreas do paciente; diminuição gradativa e precoce da sedação de três em três horas; extubação planejada, com o objetivo de prevenir a reintubação; tubo orotraqueal revestido de prata; utilização do tubo com sistema de aspiração subglótica intermitente, de modo a evitar o acúmulo de secreção acima do cuff; remoção de secreção oral antes da mudança de decúbito; extubação precoce, ou seja, retirada do tubo orotraqueal com menos de 48 horas de uso; profilaxia da úlcera péptica e profilaxia para trombose venosa (Maier et al., 2020).

As ações de enfermagem para o controle da PAV são de extrema importância dentro do contexto terapêutico e de cuidado no hospital. Acrescenta-se que a educação continuada e a adoção de medidas baseadas em evidências científicas, bem como protocolos em saúde, correspondem aos melhoramentos dos aspectos em questão. Torna-se, assim, evidente, também, como de profunda relevância, a implementação das intervenções listadas para o apoio ao serviço de Enfermagem como ato concreto que possa ser realizado pelas equipes dentro das dinâmicas hospitalares, levando em consideração métodos para evitar a PAV, conforme a maioria das publicações obtidas (França et al., 2021).

A prevenção pode diminuir o índice de pacientes acometidos por esta infecção e, consequentemente, reduzir o uso de medicamentos como os antibióticos, a permanência desses pacientes no hospital e as taxas de mortalidade associadas a esta complicação infecciosa. Os profissionais da equipe de saúde podem contribuir para prevenção dessa infecção. Dessa forma, é necessário que esses profissionais tenham conhecimentos específicos relacionados aos cuidados de prevenção para que medidas eficazes sejam adotadas (Melo et al., 2019).

Nessa perspectiva, percebe-se que o cuidado com o paciente em ventilação mecânica é foco prioritário, pois se trata de uma população com altos índices de morbimortalidade. Assim, foi criado pelo Institute for Healthcare Improvement (IHI) o 
bundle (pacote de cuidados) relacionado à ventilação onde são estabelecidas medidas com bases em evidências científicas para a prevenção da PAVM. A prática dessas medidas está relacionada à diminuição da incidência de PAVM, sendo de grande relevância a implementação do bundle de ventilação durante a assistência em Unidades de Terapia Intensiva. A adesão dos processos de educação permanente pelos profissionais é um dos focos dos hospitais de ensino, por ser uma forma de auxiliar no gerenciamento de riscos, na melhoria da assistência e, consequentemente, na redução de taxas de infecções hospitalares. Assim, as equipes das UTIs precisam estar conectadas e dispostas a construir e aderir protocolos assistenciais ou bundles (pacote de cuidados) de prevenção de pneumonia associada à ventilação mecânica (Melo et al., 2019).

O acompanhamento e o controle da taxa e densidade de incidência da PAVM são medidas preventivas para diminuir a incidência da PAVM, assim como para avaliar as intervenções e/ou ações que levam a um resultado desejável ou indesejável. O levantamento dos dados e a realização das ações voltadas ao controle de infecções dependem do envolvimento e parceria entre os profissionais da assistência e a CCIH. São recomendadas inúmeras medidas para a prevenção da PAVM, segundo a ANVISA. Deve-se calcular as taxas da PAVM, fornecer um retorno desses índices para a equipe de saúde e, sobretudo, associar tais indicadores numéricos às medidas de prevenção pertinentes. Esses valores podem se tornar um importante aliado na avaliação da qualidade da assistência (Brentini et al., 2019). A conscientização, o compromisso e a educação permanente são fatores fundamentais para que os profissionais de saúde das UTI se envolvam e contribuam de maneira efetiva na prevenção de PAVM (Pombo et al., 2010).

\section{Conclusão}

Evidenciou-se no estudo, que a pneumonia associada à ventilação mecânica (PAV) é uma causa significativa de morbidade e mortalidade em pacientes gravemente doentes em unidades de terapia intensiva (UTIs) que passam por ventilação mecânica (MV) invasiva via tubo endotraqueal (TET) ou traqueostomia. O diagnóstico precoce e a adoção de práticas conhecidas na prevenção da PAV podem reduzir a mortalidade e diminuir o desenvolvimento de organismos resistentes a múltiplos medicamentos.

É importante ressaltar que os pacientes com a idade elevada, desnutrição, condições de base graves, incluindo imunossupressão, bem como maior tempo de ventilação mecânica e de internação evidenciam maior suscetibilidade de aquisição de PAV na UTI, pois diminui a defesa do organismo causando maior exposição as IRAS.

Dessa forma, as ações de enfermagem para o controle da PAV são de extrema importância dentro do contexto terapêutico e de cuidado no hospital. Acrescenta-se que a educação continuada e a adoção de medidas baseadas em evidências científicas, bem como protocolos em saúde, correspondem aos melhoramentos dos aspectos em questão. Torna-se, assim, evidente, também, como de profunda relevância, a implementação das intervenções listadas para o apoio ao serviço de enfermagem como ato concreto que possa ser realizado pelas equipes dentro das dinâmicas hospitalares, levando em consideração métodos para evitar a PAV.

Nesse sentido, a adesão dos processos de educação permanente pelos profissionais é um dos focos dos hospitais de ensino, por ser uma forma de auxiliar no gerenciamento de riscos, na melhoria da assistência e, consequentemente, na redução de taxas de infecções hospitalares. Assim, as equipes das UTIs precisam estar conectadas e dispostas a construir e aderir protocolos assistenciais ou bundles (pacote de cuidados) de prevenção de pneumonia associada à ventilação mecânica.

Diante desse contexto, nota-se a importância do Núcleo de Segurança do Paciente (NSP) e CCIH que exibem indicadores, fiscalização dos setores, elaboração de protocolos, bundles de prevenção que são práticas que comprovadamente que evitam a PAV, atividades de educação permanente e continuada vinculada à promoção de saúde, contribuindo para ajudar a traçar estratégias de prevenção e tratamento dessa condição tão grave e que afeta um número elevado de pessoas com alcance multiprofissional nas Unidades de Terapia intensivas. Torna-se interessante a realização de estudos futuros com a finalidade de 
ampliar a produção científica a respeito dessa temática tão relevante, sendo de suma importância, no sentido de aprofundar discussões que possam contribuir para a promoção da saúde e na melhoria da qualidade de vida desses pacientes.

\section{Referências}

Alves, J. N. B., Soares, L. G., Baratieri, T., Pitilin, É. D. B., Pelazza, B. B., Zanoti-Jeronymo, D. V., \& Lentsck, M. H. (2021). Pneumonia em pacientes hospitalizados por traumas sob tratamento intensivo. Rev. enferm. UFPE on line, 1-15.

Augusto, C. A., Souza, J. P. D., Dellagnelo, E. H. L., \& Cario, S. A. F. (2013). Pesquisa Qualitativa: rigor metodológico no tratamento da teoria dos custos de transação em artigos apresentados nos congressos da Sober (2007-2011). Revista de Economia e Sociologia Rural, 51(4), 745-764.

Botelho, L. L. R., de Almeida Cunha, C. C., \& Macedo, M. (2011). O método da revisão integrativa nos estudos organizacionais. Gestão e sociedade, 5(11), 121-136.

Brentini, L. C., Araújo, E. C. S., Silveira, T. H., da Silva Negrinho, N. B., Pedigone, M. A. M., \& Brunherotti, M. A. A. (2019). Incidência de pneumonia associada à ventilação mecânica e os agentes etiológicos mais prevalentes em uma Unidade de Terapia Intensiva no interior de São Paulo. Revista de Epidemiologia e Controle de Infecção, 9(3), 227-233.

Dutra, L. A., Esteves, L. D. O., Silva, T. O. D., Resck, Z. M. R., Lima, R. S., \& Sanches, R. S. (2019). Pneumonia associada à ventilação mecânica: percepção dos profissionais de enfermagem. Rev. enferm. UFPE on line, 884-892.

Ferenhof, H. A., \& Fernandes, R. F. (2016). Desmistificando a revisão de literatura como base para redação científica: método SSF. Revista ACB, 21(3), 550563.

França, V. G. C., Lins, A. G. A., Santos, C. L. D., Ferreira, L. G. D. A., Silva, R. M. D., Almeida, T. C. D. S., \& Oliveira, D. A. L. (2021). Cuidados de enfermagem: prevenção de pneumonia associada à ventilação mecânica. Rev. enferm. UFPE on line, 1-14.

Gonçalves, F. A. F., Brasil, V. V., Minamisava, R., Caixeta, C. R., Oliveira, L. M. D. A. C., \& Cordeiro, J. A. B. L. (2012). Eficácia de estratégias educativas para ações preventivas da pneumonia associada à ventilação mecânica. Escola Anna Nery, 16, 802-808.

Kock, K. S., da Rosa, B. C., Martignago, N. N., \& Maurici, R. (2017). Pneumonia associada à Ventilação Mecânica (PAVM): incidência e desfecho clínico em uma Unidade de Terapia Intensiva no Sul de Santa Catarina. Arquivos Catarinenses de Medicina, 46(1), 02-11.

Liz, J. S., Gouvea, P. B., da Silva Acosta, A., de Araújo Sandri, J. V., de Paula, D. M., \& Maia, S. C. (2020). Cuidados multiprofissionais relacionados a prevenção da pneumonia associada à ventilação mecânica. Enfermagem em Foco, 11(2).

Lourençone, E. M. S., Branco, A., Monteiro, A. B., Fonseca, J. P., \& Caregnato, R. C. A. (2019). Adesão às medidas preventivas versus incidência de pneumonia associada à ventilação mecânica. Revista de Epidemiologia e Controle de Infecção, 9(2), 142-148.

Maier, S. R. D. O., Valim, M. D., Santos, B. D. S., Soares Júnior, J. R., \& Carrijo, M. V. N. (2020). Pneumonia associada à ventilação mecânica: evidências científicas. Rev. epidemiol. controle infecç, 103-14.

Maran, E., Spigolon, D. N., Matsuda, L. M., Teston, E. F., Oliveira, J. L. C. D., Souza, V. S. D., \& Marcon, S. S. (2020). Efeitos da utilização do bundle na prevenção de pneumonia associada à ventilação mecânica. Rev. Cuid. (Bucaramanga. 2010), e1110-e1110.

Melo, M. M., Santiago, L. M. M., Nogueira, D. L., \& Vasconcelos, M. D. F. P. (2019). Pneumonia Associada à Ventilação Mecânica: Conhecimento dos Profissionais de Saúde Acerca da Prevenção e Medidas Educativas. Rev. fundam. care, 11, 377-382.

Mendes, K. D. S., Silveira, R. C. D. C. P., \& Galvão, C. M. (2008). Revisão integrativa: método de pesquisa para a incorporação de evidências na saúde e na enfermagem. Texto \& contexto enfermagem, 17(4), 758-764.

Montini, G. R., Mestrinari, A. C. R., Rodrigues, A. M. D. S., Contrin, L. M., Werneck, A. L., \& Beccaria, L. M. (2020). Adesão ao bundle para prevenção de pneumonia associada à ventilação mecânica em terapia intensiva. Cuid Arte, Enferm, 172-180.

Pereira, A. S., Shitsuka, D. M., Parreira, F. J., \& Shitsuka, R. (2018). Metodologia da pesquisa científica.

Pombo, C. M. N., Almeida, P. C. D., \& Rodrigues, J. L. N. (2010). Conhecimento dos profissionais de saúde na Unidade de Terapia Intensiva sobre prevenção de pneumonia associada à ventilação mecânica. Ciência \& Saúde Coletiva, 15, 1061-1072.

Rodrigues, P. M. D. A., Carmo Neto, E. D., Santos, L. R. D. C., \& Knibel, M. F. (2009). Pneumonia associada à ventilação mecânica: epidemiologia e impacto na evolução clínica de pacientes em uma Unidade de Terapia Intensiva. Jornal brasileiro de pneumologia, 35, 1084-1091.

Santos, C. R. D., Costa, B. H. S., Dias, T. K. C., Guedes, H. C. D. S., Paz, M. S. S. D., Oliveira, T. C. D., ... \& Marinho, H. L. M. (2018). Fatores de risco que favorecem a pneumonia associada à ventilação mecânica. Rev. enferm. UFPE on line, 3401-3415.

Soares, C. B., Hoga, L. A. K., Peduzzi, M., Sangaleti, C., Yonekura, T., \& Silva, D. R. A. D. (2014). Revisão integrativa: conceitos e métodos utilizados na enfermagem. Revista da Escola de Enfermagem da USP, 48(2), 335-345.

Sousa, L. M. M., Marques-Vieira, C. M. A., Severino, S. S. P., \& Antunes, A. V. (2017). A metodologia de revisão integrativa da literatura em enfermagem. No21 Série 2-Novembro 2017, 17.

Souza, M. T. D., Silva, M. D. D., \& Carvalho, R. D. (2010). Revisão integrativa: o que é e como fazer. Einstein. 8(1), $102-106$. 